\title{
MUNDO-DA-VIDA E PARADIGMA: APONTAMENTOS ACERCA DA CRISE DAS CIÊNCIAS EM HUSSERL E KUHN
}

\author{
Por Devair Gonçalves Sanchez ${ }^{1}$
}

\begin{abstract}
Resumo
O presente artigo visa basicamente explorar a postura do método fenomenológico transcendental em meio à problemática da crise das ciências a partir da metade do século XIX. Na elaboração de seu método filosófico, a saber, a fenomenologia transcendental, Edmund Husserl (1859-1938) procura demonstrar que a condição do pensador no âmbito da Lebenswelt (Mundo-da-Vida) propiciará uma busca de rigor científico-filosófico mediante a aplicação conjunta de alguns conceitos aqui abordados. Num segundo momento pretende-se demonstrar qual a posição de um dos brilhantes filósofos da ciência do século XX, mediante o modus operandi das Ciências e de quem as conduz. Diante do deslinde de alguns conceitos embasados na obra A estrutura das Revoluções científicas (1962), objetiva-se apresentar o "trato teórico" de Thomas Kuhn (1922-1996) para com a atividade do cientista em meio ao processo de desenvolvimento deste saber, a partir dos primórdios do século XX.
\end{abstract}

Palavras-chave: Fenomenologia. Intersubjetividade. Transcendental.

\begin{abstract}
This article aims primarily to explore the stance of transcendental phenomenological method through the issue of the crisis of the sciences from the mid-nineteenth century. In the preparation of his philosophical method, namely, phenomenology, Edmund Husserl (1859-1938) argues that the condition of thinker around of Lebenswelt (World-Life) will provide a search of scientific-philosophical rigor by joint application of concepts covered here. Secondly we intend to demonstrate that the position of one of the brightest philosophers of science of the twentieth century, through the modus operandi of Sciences and of its leads. Before the demarcation of concepts grounded in the work-up aims at presenting tract of Thomas Kuhn (1922-1996) with the activity of the scientist in the midst of this development process to know The structure of scientific revolutions (1962), from the early twentieth century.
\end{abstract}

Keywords: Phenomenology. Intersubjectivity. Transcendental.

\section{A FENOMENOLOGIA TRANSCENDENTAL E A CRISE DAS CIÊNCIAS}

\footnotetext{
${ }^{1}$ Graduado em Filosofia (2011) pela Unioeste e Mestre em Filosofia (2014) pela mesma instituição.
} 
Retomando Descartes, imbuído da inquietação em relação ao rumo tomado pelas ciências no início do século XX, Husserl direciona sua busca por um fundamento apodítico e rigoroso, no qual todo saber científico deveria se fundamentar. Para Descartes, a filosofia era o arquétipo de todo o saber científico de sua época. Portanto, dando-se a reforma das diretrizes filosóficas, por conseguinte, ter-se-ia a mudança das ciências num todo. Tomando como protótipo metodológico as Meditações de Descartes, Husserl propõe uma espécie de "suspensão" de juízos incertos, passíveis de dúvida ou comumente admitidos. Essa suspensão consiste em pôr entre parênteses os fenômenos até que se alcance um "conjunto de dados absolutamente evidentes" (HUSSERL, 2001, p. 21).

Nas Meditações cartesianas Husserl alude ao pensador francês: "Façamos aqui, segundo os passos de Descartes, o grande gesto de voltar-se sobre si mesmo, o qual, se corretamente realizado, conduz à subjetividade transcendental: o debruçar-se sobre o ego cogito, domínio último e apoditicamente certo sobre o qual deve ser fundamentada toda filosofia radical” (HUSSERL, 2001, p. 36). Ainda, referindo-se ao projeto cartesiano, Husserl atesta que "Descartes inaugura um novo tipo de filosofia. Com ele a filosofia muda totalmente de estilo e passa radicalmente do objetivismo ingênuo ao subjetivismo transcendental" (HUSSERL, 2001, p. 22). Husserl modifica em alguns aspectos a teoria cartesiana, a fim de livrá-la dos erros que a tornam improfícua no que tange a sua adequação ao projeto fenomenológico.

No entender de Husserl, a ciência deveria ocupar-se com os dados essenciais da realidade. O mundo, aos olhos de um espectador do senso comum, portador de uma consciência passiva aos atos mundanos, torna-se um aglomerado de dados materiais, estático, sem sentido a fornecer. No entanto, aos olhos de um fenomenólogo, o mundo torna-se uma esfera de fundamentação transcendental, lugar do aparecer de fenômenos. Tendo realizado essa suspensão a fim de alcançar uma evidência apodítica primordial, para Husserl resta somente o sujeito que empreenderá a busca pelas outras certezas, percorrendo o caminho em prol do atestado da apoditicidade da ciência. A busca é por um ponto de partida para o desenvolvimento da fenomenologia transcendental. A pureza do ponto de partida é o caráter essencial da fenomenologia. Essa pureza egológica requer uma total "anulação" das diretrizes normativas atestadas pelas ciências em geral.

$\mathrm{Na}$ busca de uma verdade apodítica, o filósofo compreende que, dada a experiência comumente aceita, o procedimento da redução coloca em xeque as intenções 
não preenchidas, submetendo-as a uma sequência de experiências concordantes, ao que se acredita, darão à consciência uma síntese significante por meio das intuições. Intuir o sentido do fenômeno requer uma desconexão, parafraseando Husserl, uma "colocação entre parênteses do mundo objetivo" (HUSSERL, 2001, p. 38). Essa síntese significante pode ser entendida como a confirmação da experiência num primeiro momento; Husserl dará o nome de "evidência adequada". Cabe então à consciência a função de purificar os atos intencionais que a mesma capta em sua experiência.

Uma evidência apodítica tem essa particularidade de não ser somente, de maneira geral, certeza da existência das coisas ou dos "fatos" evidentes; ela se revela ao mesmo tempo à reflexão crítica como uma impossibilidade absoluta de que se conceba a sua não-existência e, portanto, exclui de antemão toda a dúvida imaginável como desprovida de sentido (HUSSERL, 2001, p. 33).

Partindo de um ideal de cientificidade, fundamentada no conceito de evidência, Husserl buscará com afinco uma ciência de fundamentos absolutos, colocando, num primeiro momento, em suspenso a existência do mundo. O que acontece, nas palavras de Husserl é que "a epoché fenomenológica [...] inibe o valor existencial do mundo objetivo e, dessa forma, o exclui totalmente do campo dos nossos julgamentos". Dessa forma, a ideia da existência do mundo, no âmbito da atitude natural, deverá ser recusada. Isso não quer dizer que o mundo deixe de existir, mas não deve ser ele o ponto de partida para a edificação de uma nova filosofia rigorosa, apodítica e reformadora. A radicalidade da filosofia pensada por Husserl só acontecerá se o sujeito que medita tomar como ponto de partida o ego cogito.

Somente partindo do sujeito meditante é que se pode firmar a filosofia e a ciência em terreno sólido. Nota-se que a reforma das ciências e da filosofia almejada por Husserl, dar-se-á a partir de uma transferência do campo de análise da experiência para a esfera do transcendental, no intuito de obter uma purificação dos atos cognitivos bem como do mundo em sua objetividade. "Não basta suspender nossa adesão a todas as ciências e tratá-las como pré-juízos inadmissíveis para nós. "É preciso também retirar do terreno natural, do qual elas se alimentam, do terreno do mundo empírico, sua autoridade espontânea" (HUSSERL, 2001, p. 35). Vale ressaltar que na atitude natural o sujeito se encontra, num primeiro momento, não como filósofo preocupado com o rigor da realidade, mas numa atitude conscientemente ingênua e despreocupada. Não há o esforço 
da busca, pois tudo se encontra previamente dado. Husserl não nega a existência do mundo, mas, antes de tudo, toma esse pressuposto como baluarte da fenomenologia enquanto descrição da experiência sensível. A postura diante do mundo para o fenomenólogo é guiada pela noção grega de epoché como será mostrado em seguida.

Husserl faz uso das reduções para atingir um nível de certeza cada vez mais puro. É como se a cada operação ocorresse um procedimento de filtragem das verdades alcançadas (vivências obtidas). É constante o aparecer nos escritos de Husserl de termos como "redução fillosófica", "redução eidética", "redução fenomenológica" ou "redução transcendental". Husserl entende o "modo primitivo" de atuação do cientista compreendido neste trabalho também como filósofo (pensador) - como horizonte de descobertas intangíveis. As ciências positivas se ocuparam dos setores particulares do ser e, no seu modo incipiente de averiguação, impôs como fio norteador, a questão sobre o ser do fenômeno descoberto. O Mundo-da-Vida é o âmbito acessível antes de qualquer ciência; eis o lugar da gênese do pensamento. Mais que isso, o eu puro de cada cientista ou pensador, em seu modo vivido, produz o Mundo-da-Vida.

Ao aderir a essa nova forma de ocupação meditativa, o fenomenólogo não se contenta com a demonstração de simples fenômenos, mas, abstendo-se da atitude irrefletida, passa a valorizar os dados puros vividos da consciência. Pode-se afirmar com clareza que a epoché é o ato que perpassa toda a trajetória de saída da ingenuidade irrefletida para a responsabilidade filosoficamente comprometida. A atitude tomada nesse tipo de redução implica um abandono de toda especificidade ou particularidade do sujeito. $\mathrm{O}$ Eu deve agir reflexivamente em sua esfera de vinculação. Tal esfera de vinculação dispensa a preconcepção do mundo e do Outro e predispõe o corpo como primeiro âmbito de sentido. A esfera de doação originária do ser é o lugar do transcendental. Esse âmbito inacessível a um olhar desatento surgirá a partir do intento primordial pela busca dos princípios do conhecimento.

\section{DO LEBENSWELT AO PARADIGMA - HORIZONTE E FUNDAMENTO DO PENSAR GENUÍNO}

De antemão, ressalta-se que a ciência genuína, na perspectiva husserliana, deveria preocupar-se veementemente com a reflexão acerca dos problemas de uma autêntica humanidade embasada no seu conceito essencial de racionalidade. De acordo com Husserl, "a fenomenologia deve atingir a própria verificação, enquanto filosofia 
fundamental, enquanto filosofia capaz de realizar a pretensão de um saber universal, enquanto ciência universal" (Hu VI, p. xx). Além do mais, a fenomenologia transcendental deveria ocupar-se com a análise dos fundamentos últimos de todas as ciências. Por outro lado, Kuhn desenvolve uma filosofia da ciência preocupada com o questionamento acerca do que fundamenta a evolução científica e a mudança de paradigma. Para ambos pensadores, a necessidade de delimitar e descrever a definição de critérios que abaliza a fundamentação, desenvolvimento e continuidade das ciências, como atividade de rigor, é perene em seus escritos. A necessidade de uma busca por fundamento provém da perda de sentido das ciências de um modo geral e da própria filosofia em seu momento de crise, enquanto ciência das ciências. Para Husserl, esta crise, “a crise da ciência é, pois, a crise da humanidade em nós. Nós próprios não existimos na afirmação brutal do eu sou. O eu sou só é verdadeiramente humano se se manifesta como razão, isto é, como uma liberdade" (LÉVINAS, 1997, p. 58).

Ciência, pelo viés fenomenológico, se converte em uma realização espiritual humana que, historicamente e também para todo aquele que a estuda, pressupõe não somente a saída do mundo da vida circundante, dado de modo universal comum como existente, mas que pressupõe também, continuamente, no seu exercício e prossecução, este mundo circundante na particularidade da sua autodoação para o cientista. A tarefa de toda ciência, como autêntica filosofia, em termos reduzidos, versa acerca da compreensão da vida, do mundo e do homem. Aqui é possível vislumbrar a mudança de um paradigma embasado na crença unilateral acerca da supremacia da razão, rumo ao humanismo que sustenta até mesmo, meditando de modo lato, o existencialismo pós-guerra. Husserl se apropria da noção de Ciência com base no estereótipo grego clássico, na tentativa de comunicar a função da fenomenologia em meio ao debate sobre a descrença no saber filosófico. O filósofo alemão se opõe à "convicção corrente que as ciências objetivas, positivas, são autônomas, auto-suficientes em virtude do seu método, que se pretende completamente fundamentador e, por isso, modelar" (HUSSERL, 2008, p. 127).

Para Husserl (2008, p. 119) “em termos de mundo vida, somos nele objetos entre objetos, como estando aqui e ali, na certeza simples da experiência, antes de quaisquer verificações científicas", diante disso, com base nas palavras de Xirau (1941, p. 225) "com a transformação constante do mundo da cultura humana os homens se modificam também em sua personalidade e se vêm obrigados a adotar hábitos novos de acordo com as transformações daquele". A fase da crise de Husserl caracteriza-se pelo conceito do Lebenswelt (Mundo-da-Vida). O Mundo-da-Vida é o fundamento de sentido para a 
atividade científica, e esta, portanto, não tem sua verdade e finalidade em si mesma, senão com relação ao sujeito da cotidianidade. Aqui se nota outro importante ponto de igualdade. Na fase de continuidade da ciência, enquanto Ciência Normal, a perspectiva de abertura de mundo é homogênea. Todo cientista vê o mundo de modo comum e compartilha desse mundo conforme a imposição do paradigma vigente. Ao passo, outros cientistas percebem que o mundo precisa ser visto de modo diferente. Surge a figura do pensador. O que ouve o clamor do ser, o que se movimento dentro e fora do mundo-davida.

Motivo de inúmeras pesquisas nas últimas décadas, e, por conseguinte, de uma mesma quantidade de leituras enviesadas, o tema do Lebenswelt é de grande fecundidade no âmbito da pesquisa fenomenológica husserliana. Mundo-da-Vida ou o que Fellmann denominará "paraíso esquecido" (1984, p. 117), pode ser considerado um dos estigmas do pensamento husserliano. Em meados do século XIX o descrédito na filosofia como mater cienciae era notável. A passagem do século XIX ao XX demarca um momento expressivo de interrogação acerca do sentido da humanidade e a crise de sentido das ciências humanas era latente. Oliveira (1989, pp. 82-83) declara que "para o homem de hoje, filosofia, arte e religião são realidades que não são mais aceitas em seu valor, como era o caso no mundo antigo".

Tenta fundamentar o último no primeiro, no mundo pré-científico. Segundo ele, a própria ciência emerge de algo anterior a ela mesma, do campo das experiências précientíficas e pré-categoriais, ou seja, de um a priori concreto, que chama de Lebenswelt ou Lebensumwelt. Em outras palavras, pergunta pelas condições a priori de possibilidade das ciências ao nível histórico e existencial (ZILLES, 2002, p. 31). Husserl "estava convencido que a Europa teria uma missão assinalada, inclusive privilegiada, para com a Humanidade em seu conjunto" (PATOČKA, 2004, p. 137). Antes de qualquer investida, convém assinalar que a noção de mundo (Welt) é trabalhada exaustivamente por Husserl nos escritos que antecedem Krisis. Husserl fala de um mundo circundante quotidiano “onde todos nós, e também eu que, em cada caso, filosofo, temos existência consciente, e não menos as ciências, como fatos de cultura deste mundo, com os seus cientistas e teorias" (HUSSERL, 2008, p. 118-119). "A Lebenswelt não seria um mundo fático, abstrato ou mecânico; antes, é a condição última e necessária para a vida do homem e o desenvolvimento da sua cultura" (MILONE, 2007, p. 87).

A partir de 1936 o termo mundo (Welt) é agregado ao termo no particípio (Leben). Fellmann (1984, p. 117) afirma que com o Lebenswelt "a filosofia pareceu ter sido 
redimida por fim e definitivamente da abstração que, em sua orientação especulativa e gnosiológica, a havia retirado das realidades da vida". A consciência egológica não se dissolve no âmbito da formação do mundo vivido. É a partir da mesma que se predispõem as estruturas que permitem a abertura deste mundo. Perscrutar o tema do Lebenswelt é trazer à baila discussão acerca da natureza da filosofia e do papel do filósofo na contemporaneidade. O conceito de Mundo-da-vida como proposta de reflexão na fenomenologia "tardia" equivalerá a um novo panorama acerca da investigação do sujeito e de suas relações de criação do pensar e do fazer ciência, filosofia. A abertura de mundo deve levar em consideração o âmbito pré-categorial das vivências. Descrever as estruturas que permitem essa abertura de caráter inédito no pensamento husserliano é tarefa do filósofo como funcionário da humanidade. A busca pelo desvendamento do Mundo-davida permitirá um cuidado (Sorgen) com a humanidade também afetada no seio da crise das ciências.

A noção de paradigma pode ser relacionada à de Lebenswelt com base na aproximação entre a originalidade do pensar e o movimento de dissipação da anomalia. A ciência não caminha numa via linear contínua e progressiva, mas por saltos ou revoluções. Com base no fato de que a fase $e$-laborativa de um paradigma pressupõe uma retomada do mundo da vida como ground de criação de todo o pensar. A originalidade do pensar fundamenta o paradigma. $\mathrm{O}$ estabelecimento paulatino de um paradigma equivale a "pensar o não pensado de um pensador" ${ }^{2}$. A crise das ciências clama a imposição, entendida de modo omni-englobante, "é uma crise que não atinge as ciências especializadas nos seus resultados teoréticos e práticos, mas não abala, contudo, de um lado ao outro, todo o seu sentido de verdade" (HUSSERL, 2008, p. 28). Deve-se levar a sério a indagação feita por Kuhn: "como podem tais teorias brotar da ciência normal, uma atividade que não visa realizar descobertas e menos ainda produzir teorias?" (KUHN, 2011, p. 94). A resposta está no momento pré-paradigmático, o que para a fenomenologia equivale ao âmbito pré-categorial ou ao Mundo-da-Vida. Neste âmbito dá-se a completude da originalidade do pensar. O cientista, no entanto, marginaliza o terreno précategorial. De acordo com Kuhn (2011):

A história da ciência indica que, sobretudo nos primeiros estágios de desenvolvimento de um novo paradigma, não é muito difícil inventar tais alternativas. Mas essa invenção de alternativas é precisamente o

\footnotetext{
${ }^{2}$ Para fins de uma compreensão aprofundada acerca do "pensar o não pensado", sugere-se conferir a famigerada carta de Heidegger endereçada a Husserl em 22 de outubro de 1927.
} 
que os cientistas raro empreendem, exceto durante o período préparadigmático do desenvolvimento de sua ciência e em ocasiões muito especiais de sua evolução subsequente (KUHN, 2011, p. 105).

A perspectiva kuhniana de abordagem das ciências está embasada no contato direto com a história (das ciências). Kuhn está empenhado no embate contra as teorias explicativas das ciências. Trata-se de uma investigação que privilegie o entender o progresso da ciência no âmago de si própria, em seu fazer mais elementar e cotidiano, sem, no entanto recorrer ao modo de abordagem teórico proveniente do falseacionismo ou do indutivismo. Faz-se necessário entender a noção de paradigma que está implícita em toda a teoria de Kuhn.

O movimento da crítica de Kuhn está direcionado às teorias definidoras de critérios de validação do conhecimento científico. Sua tese central defende a ideia de que o conhecimento científico não cresce de modo cumulativo e contínuo. O que se pode chamar de desenvolvimento do saber científico acontece em meio a "saltos" descontínuos, influência de fatores históricos e sociológicos, bem como do comportamento (fator psicológico) e atuação do cientista na prática. A estrutura do desenvolvimento de qualquer disciplina científica pode ser esquematizada, de acordo com Kuhn, com sua gênese calcada na fase pré-paradigmática, que estabelece a ciência normal mediante a crise e instauração do paradigma. Neste momento é que pode se trazer à baila a noção husserliana de Mundo-da-Vida.

Kuhn deixa transparecer dois tipos de segmento no que tange a noção de paradigma. Num primeiro momento a noção de paradigma está associada ao contexto norteador da pesquisa de um determinado grupo de cientistas em suas áreas específicas; num segundo momento a noção se torna mais ampla e engloba o circuito universal de atuação dos cientistas: trata-se do modelo panorâmico de atuação da prática científica. Abre se um horizonte de possibilidades que, mesmo estando em constante dinâmica, dentro de uma circunspecção, se encontra ancorado em modelos de investigação tradicionais e exemplares. Segundo Kuhn a noção de paradigma está alicerçada no campo de atuação do cientista desde o estágio incipiente até a fase de ingresso na comunidade científica. A orientação dos cientistas está embasada no paradigma vigente. Para que haja mudança é necessário um abandono coletivo do paradigma em toda sua complexidade. Quando tal movimento é desencadeado, de maneira intermitente ou não, todas as produções até então ancoradas no antigo paradigma vão se tornando obsoletas e incompatíveis com o escrutínio científico atual. 
Todo paradigma muda a partir da revolução científica. Nas palavras de Kuhn (2011, p. 125): “consideraremos revoluções científicas aqueles episódios de desenvolvimento não cumulativo nos quais um paradigma mais antigo é total ou parcialmente substituído por um novo, incompatível com o anterior”. É importante destacar que o processo de revolução científica requer diversos mecanismos de contestação do antigo paradigma e, para tanto, a transição é dividida em etapas que não se encaixam em padrões temporais específicos. Nesta etapa há uma mudança na maneira de olhar o mundo. Há em Kuhn uma espécie de "princípio da tenacidade", a saber, o cientista é um obstinado na defesa do paradigma no qual teve sua formação alicerçada. Tal modo de ação é uma maneira de autopreservação e segurança.

O paradigma sustenta e protege sua atuação, preservando o modus operandi e possibilitando a estabilidade e autonomia do cientista. Uma mudança de paradigma equivaleria à transmutação do mundo atual para um mundo estranho. Por isso não há, ou, ao menos não é confortável, o diálogo entre os cientistas no que tange a mudança de paradigma. Paradigma equivale à visão de mundo e o cientista trabalha em um mundo próprio de investigação. Kuhn está fazendo menção a uma noção de mundo onde habitam todas as perspectivas e dinâmicas de atuação do cientista. É o que ele denomina "meio ambiente". Esse meio ambiente corresponde à ciência normal, sendo que, a revolução acontece quando, dentro desse meio ambiente o paradigma estabelecido se choca com forças que o impelem a ser revisto. Tais forças se dão em meio à crise que se instaura por meio da mudança de percepção do cientista. Para Kuhn "devemos antes buscar provas indiretas e comportamentais de que um cientista com um novo paradigma vê de maneira diferente do que via anteriormente" (KUHN, p. 152).

Sobre a relação entre paradigmas como visões de mundo e a realidade material, afirma Kuhn: "Muitos leitores certamente desejarão dizer que o que muda com o paradigma é apenas a interpretação que os cientistas dão às observações que estão, elas mesmas, fixadas de uma vez por todas pela natureza do meio ambiente e pelo aparato perceptivo" (KUHN, 2011, p. 158). Do mesmo modo, Kuhn aponta a estrutura de duas fases para o que denomina "ciência madura". Lembrando que, como "ciência normal", Kuhn entende o momento de atuação de um paradigma. $\mathrm{O}$ momento anterior à vigência de um paradigma é o que ele chama de "pré-ciência". As duas fases aceitas são a da ciência normal e a ciência revolucionária. Quanto à ciência normal, diz Kuhn: “"ciência normal' significa a pesquisa firmemente baseada em uma ou mais realizações científicas passadas. Essas realizações são reconhecidas durante algum tempo por alguma 
comunidade científica específica como proporcionando os fundamentos para sua prática posterior" (KUHN, 2011, p. 29).

Vale ressaltar que Kuhn está tentando dialogar com o processo historiográfico das ciências. Em outras palavras, com o modo de se transmitir o saber científico do passado aos que no presente se dedicam à ciência. Quando as características perceptivas deixam de corresponder com a realidade percebida, se concebe como o momento da crise e, sucessivamente, da mudança de paradigma. Com o advento de um novo paradigma surge também a necessidade de dar conta de outros fatores, conceitos e reações provenientes da nova perspectiva teórica. O paradigma, em si, não é de modo algum inofensivo ao meio ambiente do cientista. Cada paradigma desencadeia um horizonte novo, fecundo e de infinitas possibilidades. Nas palavras de Kuhn (2011, p. 175), fazendo referência a Galileu, “o que parece estar envolvido aqui é a exploração por parte de um gênio das possibilidades abertas por uma alteração do paradigma medieval". No entanto, quando o quebra-cabeça (puzzles) se torna deveras complicado de resolver cabe ao cientista não se apegar fanaticamente ao paradigma antigo, mas revisitá-lo constantemente a fim de, se necessário, estabelecer critérios de demarcação pelo emprego de regras e princípios paradigmáticos fundamentais. As anomalias, portanto, tem o papel fundamental de conduzir a atividade que pode conduzir a crise e, por conseguinte, ao novo paradigma. Vale destacar que o paradigma não é abandonado enquanto não houver outro que o substitua de modo eficaz. Portanto, crise não significa abandono imediato de paradigma, mas, possibilidade de reflexão e conflitos no interior do mesmo.

\section{CONCLUSÃO}

Nota-se a equiparação e convergência entre os dois modos de pensar a originalidade e evolução do pensamento científico. Por um lado, Husserl desenvolve a noção de Lebenswelt como o horizonte por excelência pelo qual deve se guiar todo pensador, inclusive o cientista. Por outro, Kuhn estabelece a noção de paradigma como força motriz do avanço teórico das ciências. Tanto para um quanto para outro, seja o cientista ou o pensador (filósofo), a atividade atual do paradigma e a disposição do Mundo-da-Vida enquanto espaço do agente cambiador do paradigma, são indissociáveis. Para ambos pensadores é a verdade que orienta os rumos das ciências. A motivação gerada pela necessidade de se estabelecer o que seja verdadeiro surge no âmbito do 
mundo da vida e atinge os recônditos inexplorados da atividade do cientista, seja o agente laboratorial, seja o pesquisador de filosofia. O paradigma não promove a estagnação do processo de inovação e evolução do conhecimento. Pelo contrário, o paradigma estimula o conflito e a revisitação no que tange ao antigo paradigma. Nas palavras de Kuhn (2011, p. 26) "uma nova teoria, por mais particular que seja seu âmbito de aplicação, nunca ou quase nunca é um mero incremento ao que já é conhecido. Sua assimilação requer a reconstrução da teoria precedente e a reavaliação dos fatos anteriores". A filosofia não estabelece paradigmas, mas está constantemente empenhada com as possibilidades trazer a luz o velado. Trata-se da noção grega de verdade (alethéia). Pensar o não pensado aperfeiçoa o paradigma não por si mesmo, mas pela originalidade do pensador que o faz.

\section{REFERÊNCIAS BIBLIOGRÁFICAS}

BENOIST, Jocelyn. (1998). O Mundo para Todos: Universalidade e Lebenswelt no Último Husserl. Tradução de Sílvio Rosa Filho. Revista Discurso (29). Páginas 208-38.

FELLMANN, Ferdinand. (1984). Fenomenologia y Expresionismo. Tradução de Enrique Müller del Castillo. Editorial Alfa.

HUSSERL, Edmund. Conferências de Paris. Tradução de António Fidalgo e Artur Morão. Edições 70: Rio de Janeiro, RJ. 1992.

. (2001). Méditations Cartésiennes. Trad.G. Peiffer e E. Lévinas, Paris: Vrin, 1996. Trad. brasileira (Frank de Oliveira): Meditações Cartesianas. São Paulo: Madras, 2001.

(2008). A Crise das Ciências Européias e a Fenomenologia Transcendental. Uma Introdução à Filosofia Fenomenológica. Tradução de Diogo Falcão Ferrer. Universitas Olisiponensis. Centro de Filosofia da Universidade de Lisboa.

. (2002). A crise da humanidade europeia e a filosofia. Introdução e tradução de Urbano Zilles. EDIPUCRS. $2^{\text {a }}$ Edição. Porto Alegre: Coleção Filosofia 41.

Portugal.

(1989) A Ideia da Fenomenologia. Tradução de Artur Morão. Edições 70.

KELKEL, Arion L. SCHÉRER, René. (1954). Husserl. Tradução de Joaquim João Coelho Rosa. Edições 70.

KELLER, Pierre. (1999). Husserl and Heidegger on human experience. Cambridge university press. New York.

KUHN, Thomas Samuel. (2011). A estrutura das revoluções científicas. Tradução de Beatriz Vianna Boeira e Nelson Boeira. São Paulo: Perspectiva. (série Debates - Ciência). 
LÉVINAS, E. (1997). Descobrindo a existência com Husserl e Heidegger. Tradução de Fernanda Oliveira. Lisboa: Instituto Piaget.

MILONE, Raúl Alberto. (2007). Lebenswelt Husserliana y concepción semántica de las teorías. Ideas y Valores. Número 135. Bogotá, Colombia. Páginas 85-94.

OLIVEIRA, Manfredo Araújo de. (1989). A Filosofia na crise da Modernidade. Edições Loyola, São Paulo, Brasil.

PATOČKA, Jan. (2004). El movimento de la existencia humana. Tradução de Teresa Padilla, Jesús María Ayuso e Agustín Serrano de Haro. Ediciones Encuentro, S.A, Madrid.

XIRAU, J. (1941). La Filosofía de Husserl. Una introducción a la Fenomenología.

ZILLES, Urbano. (2001). Os Conceitos Husserlianos de Lebenswelt e Teleologia. In: Souza, R.E.; Oliveira, N. Fenomenologia Hoje: existência, ser e sentido no alvorecer do século XXI. Porto Alegre: EDIPUCRS. 